\title{
Highlight report: $N$-acetyltransferase 2 and urinary bladder cancer risk
}

\author{
Meinolf Blaszkewicz ${ }^{1}$
}

Received: 24 May 2017 / Accepted: 29 May 2017 / Published online: 2 June 2017

(C) Springer-Verlag Berlin Heidelberg 2017

In recent years, genome-wide association studies have identified and validated a set of genetic variants that are associated with urinary bladder cancer risk (e.g., Figueroa et al. 2016; Rafnar et al. 2014; Selinski 2014a, b; Selinski et al. 2012, 2013; Kiemeney et al. 2010; review: Golka et al. 2011). After identification of the most relevant individual variants, it became possible to identify SNP interactions (Schwender et al. 2015) and to differentiate the contribution of genetic predisposition and occupational exposure to urinary bladder cancer risk (Selinski et al. 2016; Krech et al. 2013, 2016).

Recently, it has become clear that at least one of these genetic variants, NAT2*6A/*6A is not only associated with increased risk to develop bladder cancer, but also with prognosis of bladder cancer patients (Selinski et al. 2017). NAT2*6A/*6A leads to a particularly slow enzymatic activity of $\mathrm{N}$-acetyltransferase 2 , the so-called ultra-slow acetylator (Selinski et al. 2014; Ruiz et al. 2012; Patillon et al. 2014). In the lately published study with 586 urinary bladder cancer patients, ultra-slow acetylators were shown to have a higher recurrence risk and a shorter recurrencefree time compared to genotypes associated with a more rapid acetylation phenotype (Selinski et al. 2017). This association was particularly strong in smokers. The result is of high interest, since a higher risk of recurrence in NAT2 $* 6 \mathrm{~A} / * 6$ A patients justifies a more intensive monitoring of this subgroup after surgery. Progress in the field of the prognostic relevance of genetic variants on prognosis of

Meinolf Blaszkewicz

blaszkewicz@ifado.de

IfADo-Leibniz Research Centre for Working Environment and Human Factors at TU Dortmund, Ardeystr. 67, 44139 Dortmund, Germany bladder cancer is currently hampered by the lack of large cohorts with available DNA and a carefully established follow-up. Nevertheless, one of the most important steps in future will be to analyze also all other risk variants identified in genome-wide association studies with respect to their prognostic relevance after surgery of bladder cancer.

\section{References}

Figueroa JD, Middlebrooks CD, Banday AR, Silverman DT, Prokunina-Olsson L, Rothman N (2016) Identification of a novel susceptibility locus at $13 \mathrm{q} 34$ and refinement of the $20 \mathrm{p} 12.2$ region as a multi-signal locus associated with bladder cancer risk in individuals of European ancestry. Hum Mol Genet 25(6):1203-1214. doi:10.1093/hmg/ddv492 (Epub 2016 Jan 4)

Golka K, Selinski S, Lehmann ML, Blaszkewicz M, Marchan R, Ickstadt K, Schwender H, Bolt HM, Hengstler JG (2011) Genetic variants in urinary bladder cancer: collective power of the "wimp SNPs". Arch Toxicol 85(6):539-554. doi:10.1007/s00204-0110676-3 (Epub 2011 Mar 5. Review)

Kiemeney LA, Sulem P, Besenbacher S, Knowles MA, Rafnar T, Stefansson K (2010) A sequence variant at 4p16.3 confers susceptibility to urinary bladder cancer. Nat Genet 42(5):415-419. doi:10.1038/ng.558 (Epub 2010 Mar 28)

Krech K, Fu HY, Thiele W, Ruf S, Schöttler MA, Bock R (2013) Reverse genetics in complex multigene operons by co-transformation of the plastid genome and its application to the open reading frame previously designated psbN. Plant J 75(6):10621074. doi:10.1111/tpj.12256 (Epub 2013 Jun 26)

Krech S, Selinski S, Bürger H, Hengstler JG, Jedrusik P, Hodzic J, Knopf HJ, Golka K (2016) Occupational risk factors for prostate cancer in an area of former coal, iron, and steel industries in Germany. Part 2: results from a study performed in the 1990s. J Toxicol Environ Health A 79(22-23):1130-1135

Patillon B, Luisi P, Poloni ES, Boukouvala S, Darlu P, Genin E, Sabbagh A (2014) A homogenizing process of selection has maintained an "ultra-slow" acetylation NAT2 variant in humans. Hum Biol 86(3):185-214

Rafnar T, Sulem P, Thorleifsson G, Thorsteinsdottir U, Kiemeney LA, Stefansson K (2014) Genome-wide association study yields 
variants at $20 \mathrm{p} 12.2$ that associate with urinary bladder cancer. Hum Mol Genet 23(20):5545-5557. doi:10.1093/hmg/ddu264 (Epub 2014 May 26)

Ruiz JD, Martínez C, Anderson K, Gross M, Lang NP, García-Martín E, Agúndez JA (2012) The differential effect of NAT2 variant alleles permits refinement in phenotype inference and identifies a very slow acetylation genotype. PLoS One 7(9):e44629. doi:10.1371/journal.pone.0044629 Epub 2012 Sep 6

Schwender H, Selinski S, Blaszkewicz M, Marchan R, Ickstadt K, Golka K, Hengstler JG (2015) Correction: distinct SNP combinations confer susceptibility to urinary bladder cancer in smokers and non-smokers. PLoS One 10(9):e0137937. doi:10.1371/journal.pone.0137937 (eCollection 2015. No abstract available)

Selinski S (2014a) Impact of urinary bladder cancer risk variants on prognosis and survival. EXCLI J 13:1254-1258 (eCollection 2014. No abstract available)

Selinski S (2014b) The post GWAS era: strategies to identify genegene and gene-environment interactions in urinary bladder cancer. EXCLI J 13:1198-1203 (eCollection 2014. No abstract available)

Selinski S, Lehmann ML, Blaszkewicz M, Ickstadt K, Hengstler JG, Golka K (2012) Rs11892031[A] on chromosome 2q37 in an intronic region of the UGT1A locus is associated with urinary bladder cancer risk. Arch Toxicol 86(9):1369-1378. doi:10.1007/ s00204-012-0854-y (Epub 2012 Apr 25)

Selinski S, Blaszkewicz M, Ickstadt K, Hengstler JG, Golka K (2013) Refinement of the prediction of $\mathrm{N}$-acetyltransferase 2 (NAT2) phenotypes with respect to enzyme activity and urinary bladder cancer risk. Arch Toxicol 87(12):2129-2139. doi:10.1007/ s00204-013-1157-7 (Epub 2013 Nov 13)

Selinski S, Blaszkewicz M, Ickstadt K, Hengstler JG, Golka K (2014) Improvements in algorithms for phenotype inference: the NAT2 example. Curr Drug Metab 15(2):233-249

Selinski S, Bürger H, Blaszkewicz M, Otto T, Volkert F, Moormann O, Niedner H, Hengstler JG, Golka K (2016) Occupational risk factors for relapse-free survival in bladder cancer patients. J Toxicol Environ Health A 79(22-23):1136-1143

Selinski S, Gerullis H, Otto T, Roth E, Volkert F, Ovsiannikov D, Salem J, Moormann O, Geis BC, Niedner H, Blaszkewicz M, Hengstler JG, Golka K (2017) Ultra-slow N-Acetyltransferase 2 Is associated with recurrence-free time in bladder cancer patients. Eur Urol 71(6):994-995. doi:10.1016/j.eururo.2016.12.007 (Epub 2016 Dec 28. No abstract available) 